\title{
Evaluation of a resource to facilitate implementation of UK eatwell plate advice
}

\author{
W. S. Leslie ${ }^{1}$, L. Murray ${ }^{2}$, J. Eunson ${ }^{2}$, N. Burrough ${ }^{2}$, F. Comrie ${ }^{3}$, M. E. J. Lean ${ }^{1}$ and C. R. Hankey ${ }^{1}$ \\ ${ }^{1}$ School of Medicine, University of Glasgow, Glasgow Royal Infirmary, Glasgow G4 OSF, UK, ${ }^{2}$ Ipsos MORI, 4 Wemyss \\ Place, Edinburgh EH3 6DH, UK and ${ }^{3}$ Food Standards Agency in Scotland, St Magnus House, Guild Street, Aberdeen
}

$A B 116 N J$

The eatwell plate provides consumers and organisations in the UK with consistent visual messaging on the requirements for a healthy balanced diet. To assist in translating and applying this advice, a new resource, the eatwell week, was designed to present a practical example of a 7-day menu which meets UK Dietary References Values (DRVs) and dietary targets. Evaluation of the resource, to determine clarity, understanding, relevance, acceptability, usability and test its appeal and effectiveness, was carried out by an independent research agency (Ipsos MORI). Focus groups were held in four UK locations, with consumers with different cooking habits and demographic characteristics. Testing was also conducted with health professionals (practice nurses, cardiac rehabilitation nurses, dietitians, occupational health nurses and health promotion specialists).

Reactions to the style and presentation of the resource were positive. Most appealing were the split pages which conveyed the message that meals \& snacks from different days were interchangeable:

"this is quirky \& modern, less boring, there is something to be said about the way it has been designed" (Dietitian - London)

The inclusion of photographs increased engagement with the resource \& proved a useful guide in the preparation of meals

$$
\begin{gathered}
\text { "really helps a lot giving you, you know what it's supposed to look like when you're } \\
\text { finished"(Female - Lewisham) }
\end{gathered}
$$

The resource was perceived to fill a gap in current resources, but was regarded as unsuitable for cultural minority groups. Health professionals felt the purpose of the eatwell week was unclear and were unsure who it was intended for. Dietitians felt it would not help people to lose weight, so was of limited use to them. The use of popular, familiar foods addressed the barrier of acceptability. Despite $\%$ energy from carbohydrate being close to the DRV each day, consumers and some health professionals felt that there was a lot, perhaps even too much, bread (and other sources of carbohydrate) in the eatwell week. Consumers and health professionals had thought there would be more salad and vegetables which was interesting as the week exceeded the daily 5-a-day target for fruit \& vegetables

$$
\begin{aligned}
& \text { "it's not just all vegetables \& steamed fish" (Health professional - Falkirk) } \\
& \text { "I never thought or expected to see apple crumble or chocolate biscuits" (Female - Dundee) }
\end{aligned}
$$

Consumers found the recipes simple, which encouraged them to cook, although preparation time was a barrier.

"I felt like a gourmet chef" (Female - Lewisham)

"I won't be able to stick to any of those, I know for a fact I won't. The fact is time, when I come home I don't want to be slaving down the cooker cooking one of these things,

$$
\text { I'm too tired" (Male - Salford) }
$$

However, the message of the balance of food groups in a healthy balanced diet was poorly understood as some consumers perceived all foods in the eatwell week as 'healthy'. Consumers often lacked the knowledge to make informed substitutions in the 'week'.

There is need to emphasise the role of healthy eating in obesity and disease prevention. Focus group responses may be undermined by the poor understanding of the correct composition of a healthy diet shown by participants. Further information is needed within the eatwell week resource to help users implement the principles of the UK eatwell plate. This should include information on adaptation of recipes and meals to facilitate sustained use of the eatwell week. Focus group data has informed revision of the eatwell week.

Foods Standards Agency Scotland commissioned this work 